\title{
Estimating the Value of New Technologies That Provide More Accurate Drug Adherence Information to Providers for Their Patients with Schizophrenia
}

\author{
Jason Shafrin, PhD; Taylor T. Schwartz, MPH; Darius N. Lakdawalla, PhD; and Felicia M. Forma, BSc
}

\begin{abstract}
BACKGROUND: Nonadherence to antipsychotic medication among patients with schizophrenia results in poor symptom management and increased health care and other costs. Despite its health impact, medication adherence remains difficult to accurately assess. New technologies offer the possibility of real-time patient monitoring data on adherence, which may in turn improve clinical decision making. However, the economic benefit of accurate patient drug adherence information (PDAl) has yet to be evaluated.
\end{abstract}

OBJECTIVE: To quantify how more accurate PDAI can generate value to payers by improving health care provider decision making in the treatment of patients with schizophrenia.

METHODS: A 3-step decision tree modeling framework was used to measure the effect of PDAI on annual costs (2016 U.S. dollars) for patients with schizophrenia who initiated therapy with an atypical antipsychotic. The first step classified patients using 3 attributes: adherence to antipsychotic medication, medication tolerance, and response to therapy conditional on medication adherence. The prevalence of each characteristic was determined from claims database analysis and literature reviews. The second step modeled the effect of PDAI on provider treatment decisions based on health care providers' survey responses to schizophrenia case vignettes. In the survey, providers were randomized to vignettes with access to PDAI and with no access. In the third step, the economic implications of alternative provider decisions were identified from published peer-reviewed studies. The simulation model calculated the total economic value of PDAI as the difference between expected annual patient total cost corresponding to provider decisions made with or without PDAI.

RESULTS: In claims data, $75.3 \%$ of patients with schizophrenia were found to be nonadherent to their antipsychotic medications. Review of the literature revealed that $7 \%$ of patients cannot tolerate medication, and $72.9 \%$ would respond to antipsychotic medication if adherent. Survey responses by providers $(n=219)$ showed that access to PDAl would significantly alter treatment decisions for nonadherent or adherent/poorly controlled patients $(P<0.001)$. Payers can expect to save $\$ 3,560$ annually per nonadherent patient who would respond to therapy if adherent. Savings increased to $\$ 9,107$ per nonadherent patient when PDAl was given to providers who frequently augmented therapy for these patients. Among all poorly controlled patients (i.e., the nonadherent or those who were adherent but unresponsive to therapy), access to PDAI decreased annual patient cost by $\$ 2,232$. Savings for this group increased to $\$ 7,124$ per patient when PDAI was given to providers who frequently augmented therapy.

CONCLUSIONS: Access to PDAl significantly improved provider decision making, leading to lower annual health care costs for patients who were nonadherent or adherent but poorly controlled. Additional research is warranted to evaluate how new technologies that accurately monitor adherence would affect health and economic outcomes among patients with serious mental illness.

J Manag Care Spec Pharm. 2016;22(11):1285-91

Copyright $\odot 2016$, Academy of Managed Care Pharmacy. All rights reserved.

\section{What is already known about this subject}

Medication adherence greatly affects outcomes for patients with serious mental illness.

New technology is being developed to give health care providers more accurate information about patient adherence to medication.

\section{What this study adds}

This study estimates the cost savings that accrue when providers gain access to accurate antipsychotic adherence information for patients with schizophrenia.

A decision tree model is used to incorporate data from a claims database analysis, literature review, and provider survey.

Study findings indicate that cost savings would be greatest for nonadherent patients, patients with poorly controlled illness, and patients who are treated by providers who routinely augment antipsychotic therapy.

$\mathrm{M}$ edication nonadherence is common among patients with schizophrenia and has been demonstrated to be costly. ${ }^{1,2}$ Specifically, nonadherence to antipsychotic medication is associated with relapse, high rates of psychiatric hospitalization, poor functional outcomes, and increased health care costs. ${ }^{3,4}$

Despite its importance, patient adherence is difficult to assess accurately, and all currently used methods to monitor adherence have considerable limitations., ${ }^{5,6}$ In clinical practice, patient self-report is commonly used to measure adherence, ${ }^{7}$ but it is subject to recall bias. Proportion of days covered (PDC) and other measures that use data from prescription fills can provide an estimate of how much medication a patient had available, but they do not indicate whether and when the medication was taken. Adding to the uncertainty, different methods of assessing adherence can yield highly variable estimates. ${ }^{7,8}$ One claims analysis reported that $94 \%$ of patients with lowto-moderate adherence based on PDC $\leq 70 \%$ were assessed by their physicians to have high adherence (taking medication as prescribed $>70 \%$ of the time). ${ }^{8}$

The advent of wearable technology, video observation, and digital medicine offers the possibility of obtaining more objective and reliable patient-level data on medication 
TABLE 1 Patient Attributes Used in Economic Model

\begin{tabular}{|c|c|c|c|c|}
\hline \multirow[b]{2}{*}{ Patient Attribute } & \multicolumn{2}{|r|}{ Baseline } & \multicolumn{2}{|c|}{ Sensitivity Analysis } \\
\hline & Proportion (\%) & Source & Proportion (\%) & Source \\
\hline Adherent (PDC $\geq 80 \%)$ & 24.7 & $\begin{array}{c}\text { MarketScan (claims data) 2007-2014 } \\
\text { Humana (claims data) 2007-2012 }\end{array}$ & $40.0^{\mathrm{a}}$ & Kane et al., $2013^{1}$ \\
\hline Does not tolerate medication & 7.0 & Marder et al., $2003^{14}$ & 20.0 & Assumption \\
\hline Responds to treatment if adherent & 72.9 & Pigott et al., $2003^{15}$ & $\begin{array}{l}90.0 \\
60.0\end{array}$ & $\begin{array}{l}\text { Kane et al., } 2002^{38} \\
\text { Assumption }\end{array}$ \\
\hline
\end{tabular}

aThe $40 \%$ proportion represents the median adherence rates among nonrandomized controlled trials evaluated in this study.

$P D C=$ proportion of days covered.

adherence. ${ }^{9,10}$ One technology, Video Directly Observed Therapy (VDOT), was developed to allow remote or automated observation and verification of medication ingestion. With VDOT, an observer watches the patient take the medication through live or recorded video. ${ }^{11,12}$ More recently, a new digital medicine system designed to measure medication ingestion through a sensor embedded in a medication tablet is being developed. ${ }^{6,13}$ When the tablet reaches the stomach, it signals a wearable sensor, which in turn communicates the ingestion to a smartphone application and eventually the patient's provider.

The economic benefits of these adherence technologies for patients with schizophrenia, however, have not been studied. The purpose of this analysis was to quantify the value of patient drug adherence information (PDAI) in reducing health care costs by improving health care provider treatment decisions for patients with schizophrenia.

\section{Methods}

This study used a 3-step decision tree modeling framework. First, patients were classified using 3 binary attributes: whether they were adherent to their atypical antipsychotic; whether they would be able to tolerate their atypical antipsychotic if they adhered; and whether they would respond to the treatment if they adhered to it and tolerated it. Since the value of adherence information varies across patient characteristics, this first step accounts for a few salient aspects of clinical diversity in the schizophrenia patient population. Second, the model estimated the likelihood that PDAI would affect provider treatment decisions for patients of different types. These estimates were derived from a provider survey, in which half of the respondents had access to PDAI and half did not. Third, changes in provider treatment decisions were modeled to indicate how likely they were to affect annual patient cost, conditional on patient type. For instance, for patients who were not adherent to their atypical antipsychotics, switching them to long-acting injectables (LAIs) would result in cost reductions. For patients who were not responding to treatment but were already adherent to their atypical oral antipsychotics, use of LAIs would increase cost.
The economic value of accurate and accessible PDAI was calculated as the difference between the expected annual patient total cost from the payer's perspective when providers made decisions with and without PDAI. Economic values were reported across all providers and for the subgroup of providers who frequently augmented antipsychotic therapy when patients were poorly controlled.

\section{Step 1: Stratify Patients Using 3 Key Attributes}

Since the effects of PDAI are likely to vary across patients, the study framework accounted for variation using 3 attributes: adherence to antipsychotic medication, medication tolerance, and response to therapy conditional on medication adherence. The model then used binary characteristics for each of the 3 dimensions of variation. Thus, there were $8\left(2^{3}\right)$ patient types modeled (e.g., adherent, tolerant of the drug, and responsive to therapy). The share of patients who were adherent to their medications was estimated from claims data, whereas the share of patients who tolerated the medication and responded to therapy conditional on adherence was estimated from the literature (Table 1). ${ }^{14,15}$

To estimate the share of patients who were adherent to their atypical antipsychotics, an analysis was conducted using claims databases for commercial insurance (Truven Health MarketScan Commercial Claims and Encounters Database from the fourth quarter [Q4] of 2007 through Q4 of 2013); Medicaid (Truven Health MarketScan Multi-State Medicaid Database from Q4 of 2007 through Q4 of 2013); and Medicare (Humana Medicare claims data from 2007 through 2012). Patients' diagnoses were identified in the databases according to International Classification of Diseases, Ninth Revision, Clinical Modification (ICD-9-CM) diagnosis codes. Patients included in the calculations met the following criteria: $\geq 1$ claim with a schizophrenia (ICD-9-CM code 295.x) diagnosis code during the continuous enrollment period; aged $\geq 18$ years at the index date, defined as the first observed fill of an oral atypical antipsychotic; filled a prescription for an oral atypical antipsychotic; initiated an antipsychotic after a 6-month clean period; continuously enrolled 6 months before the index date with no filled prescriptions for an atypical or typical antipsychotic 


\begin{tabular}{|c|c|c|}
\hline Medical Treatment Decision & $\begin{array}{l}\text { Annual Per Patient } \\
\text { Change in Costs } \\
\text { (2016 USD) }\end{array}$ & Source \\
\hline Unnecessary medication change & 4,079 & Faries et al., 200918 \\
\hline Necessary medication change & $-3,570$ & Faries et al., $2009^{22}$ \\
\hline Augmentation of therapy & 4,417 & $\begin{array}{l}\text { Faries et al., } 2005^{17} \\
\text { Valuck et al., } 2007^{19}\end{array}$ \\
\hline $\begin{array}{l}\text { Switch to long-acting injectable } \\
\text { formulation for nonadherent } \\
\text { patients }\end{array}$ & $-7,925$ & Lin et al., 201320 \\
\hline $\begin{array}{l}\text { Switch to long-acting injectable } \\
\text { for adherent patients }\end{array}$ & 1,713 & Lin et al., $2013^{20}$ \\
\hline Change in dose & 0 & Assumption \\
\hline
\end{tabular}

during this time; and continuously enrolled for $\geq 12$ months after the index date.

Adherence was measured based on the share of patients with $\mathrm{PDC} \geq 80 \%$, measured over the 12 -month period following the initiation of antipsychotic therapy. ${ }^{16}$

\section{Step 2: Assess Effect of PDAI on Provider Treatment Choices}

Since there is little existing real-world data on the use of accurate, real-time PDAI, this study's approach was based on a cross-sectional survey that presented clinical vignettes to providers. "Experimental" and "control" vignettes featured patients with PDAI and identical patient vignettes without PDAI, respectively. The providers responding to the survey were randomized across the experimental and control vignettes to determine how PDAI is likely to affect treatment decision making.

The vignettes were derived from published cases that described patients with schizophrenia. Vignettes included 3 types of patients: nonadherent; adherent, poorly controlled; and adherent, well controlled. For each vignette, respondents selected 1 of 6 pharmacological treatment decisions: monitor patient stability; switch to another oral antipsychotic; use an LAI antipsychotic; augment with another antipsychotic; augment with a medication from another drug class (e.g., antidepressant or mood stabilizer); or increase the dose of the current medication. Providers including physicians, physician assistants, and nurse practitioners were invited by e-mail, fax, or mail to participate in the survey.

\section{Step 3: Estimate Effect of Treatment Choices on Cost Outcomes}

The economic model incorporated the probability of falling into 1 of the 8 patient categories, the provider treatment decisions faced for each patient category, and annual health care costs that resulted from a given set of treatment choices acting upon a particular category of patient. Information from published peer-reviewed studies was used to identify health economic outcomes and costs conditional on patient adherence and provider decisions (Table 2). ${ }^{17-20}$ All costs were inflated to 2016 U.S. dollars using the Consumer Price Index from the Bureau of Labor Statistics. ${ }^{21}$ Cost parameters included cost of switching antipsychotics; cost of augmentation (including augmentation with another antipsychotic and with a medication from another class); change in costs with adherence interventions (e.g., switching from an oral to LAI antipsychotic); and cost of dose increase. Costs were measured as total costincluding inpatient, outpatient, and pharmacy_-but the cost of the technology providing the PDAI was not included.

\section{Sensitivity Analysis}

In addition to the baseline model, the cost-saving estimate's sensitivity to key parameter values was tested. In Step 1, sensitivity of all parameter values was tested (Table 1). For Step 2, the effect on cost saving was examined when provider use of LAI increased or decreased by 10 percentage points among poorly controlled patients. Finally, for Step 3 the effect of what happened when unnecessary switching and augmentation cost increased or decreased by $25 \%$ was tested. Although the baseline specification assumed that changing patient medication had no effect on cost, in the sensitivity analysis, it was also examined how cost-saving estimates would change if improved dose titration resulted in an annual cost saving of $\$ 1,000$.

\section{Results}

\section{Patient Attributes and Costs of Medical Decisions}

Insurance claims analyses of 39,746 patients with schizophrenia revealed that $75.3 \%$ were nonadherent to their antipsychotic medications (PDC $<80 \%$; Table 1). Based on estimates from the literature review, this economic model was parameterized so that $7 \%$ of patients with schizophrenia would not tolerate antipsychotic medication and that $72.9 \%$ of patients with schizophrenia would respond to treatment if they were adherent to their medications. ${ }^{14,15}$ Costs associated with various scenarios were estimated from the literature (Table 2) ${ }^{17-20,22}$ Substantial changes in cost were expected with necessary switches to other oral antipsychotics for adherent, poorly controlled patients, or with a switch to LAIs for nonadherent patients.

\section{Effect of PDAl on Prescribing Decisions}

Survey responses $(n=219)$ showed that access to PDAI affected provider treatment decisions for nonadherent patients and adherent, poorly controlled patients. Regardless of whether they had access to PDAI, providers were most likely to choose monitoring of clinical stability for adherent and well-controlled patients. For nonadherent patients (regardless of disease control), most providers who had PDAI opted to switch treatment to an LAI, while very few chose to increase the dose of the 


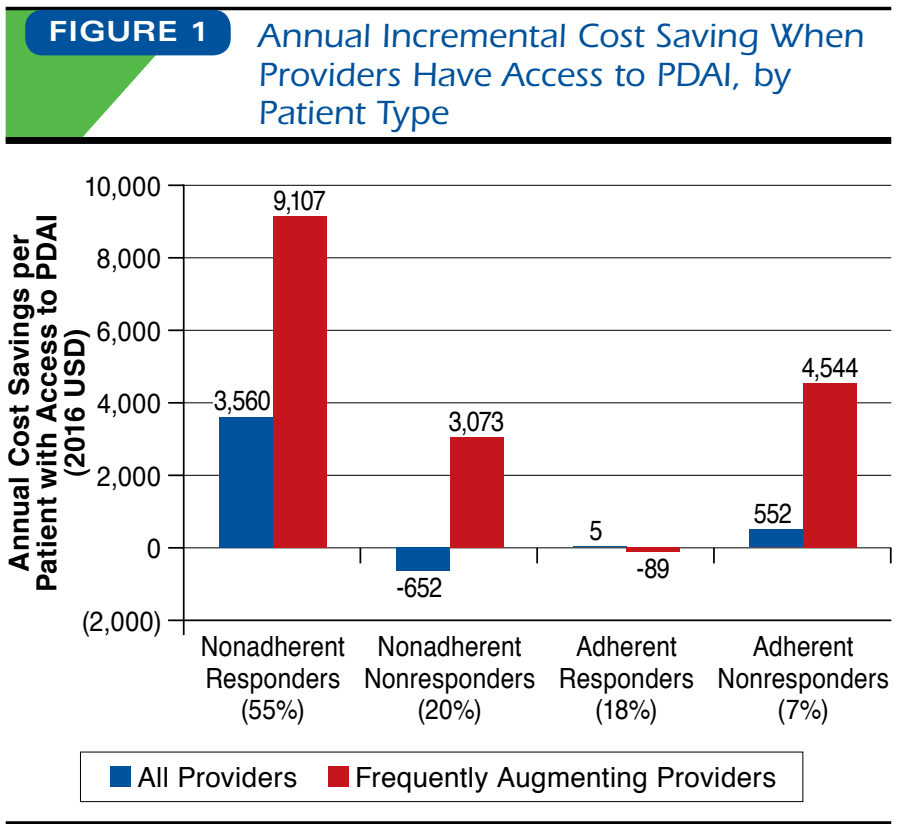

Note: Larger positive numbers indicate more cost saving; negative numbers indicate negative cost saving (i.e., costs increased).

PDAI = patient drug adherence information; USD = U.S. dollars.

current oral antipsychotic or switch to another oral antipsychotic. However, those who did not have PDAI available opted to increase the dose of the current oral antipsychotic, switch to an LAI, or monitor clinical stability with similar frequency for nonadherent patients. The decisions made by providers with and without PDAI were significantly different for this group of patients $(P<0.001)$. Conversely, for adherent, poorly controlled patients, providers with access to PDAI were significantly less likely to prescribe an LAI and more likely to increase medication dose than providers who did not have access to PDAI $(P<0.001)$.

\section{Effect of PDAI on Annual Patient Costs}

Based on the parameters already described, 55\% of patients were nonadherent but would respond to therapy if adherent, while another $20 \%$ of patients were nonadherent but would not respond to therapy if adherent. Adherent patients who would respond to therapy (adherent, well controlled) comprised 18\% of the population, and $7 \%$ of patients were adherent but would not respond to the current therapy.

Since physicians do not know a priori which patients will respond to therapy, PDAI is more valuable for patients who respond to treatment and less valuable, or even costly, for patients who do not. As expected, PDAI produced little to no change in cost for adherent, well controlled patients. However, PDAI reduced cost the most for nonadherent patients who would respond to therapy if adherent ( $\$ 3,560$ cost saving), while costs were expected to increase with provider access

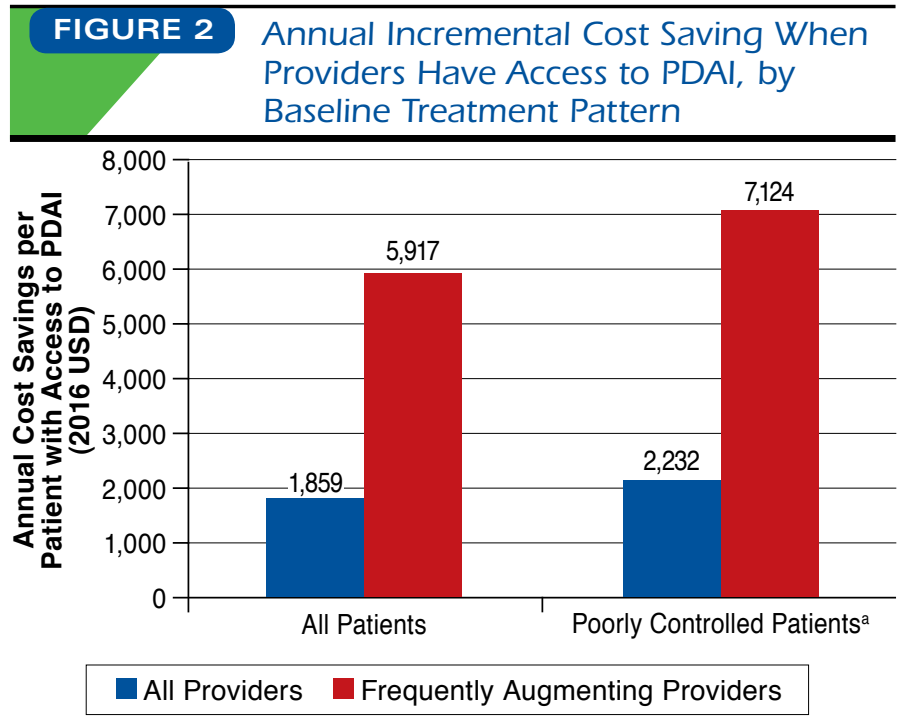

Note: Larger positive numbers indicate more cost saving; negative numbers indicate negative cost saving (i.e., costs increased).

aPoorly controlled patients include nonadherent patients and adherent patients who do not respond to the current treatment.

$P D A I=$ patient drug adherence information; USD =U.S. dollars

to PDAI for a patient who was nonadherent but would not respond to treatment if adherent (\$652 cost increase). When the analysis was limited to those providers who frequently augmented therapy for poorly controlled patients, changes in cost ranged from an $\$ 89$ cost increase for adherent patients already responding to therapy to a $\$ 9,107$ cost saving for nonadherent responders (Figure 1).

Poorly controlled patients included those who were nonadherent and those who were adherent but not responding to therapy. Among these poorly controlled patients, provider access to the patient's PDAI reduced annual patient cost by $\$ 2,232$, compared with cases in which providers did not have access to PDAI. If providers who frequently increased the number of medications used to treat the patient's symptoms had access to PDAI, potential annual reductions in cost could be as high as $\$ 7,124$ when applied to poorly controlled patients (Figure 2).

The sensitivity analysis revealed that these results were most sensitive to the ability of LAIs to reduce cost and patient response rate. Like any diagnostic tool, PDAI only results in cost savings if there are effective treatments available, so it should not be surprising that the benefit of PDAI depends largely on these 2 parameters. Changing these parameters can result in up to $24.3 \%$ less cost saving or $34.3 \%$ more cost saving than was estimated in the baseline model (Table 3). All other parameter changes resulted in cost saving estimates that changed by less than $\pm 10 \%$. 
TABLE 3 Sensitivity Analysis: Annual Incremental Cost Saving When Providers Have Access to PDAI

\begin{tabular}{|c|c|c|c|c|c|c|}
\hline \multicolumn{3}{|l|}{ Parameters } & \multicolumn{2}{|c|}{ All Patients } & \multicolumn{2}{|c|}{ Poorly Controlled Patients ${ }^{a}$} \\
\hline Change in Parameter Value & $\begin{array}{l}\text { Baseline } \\
\text { Value }\end{array}$ & $\begin{array}{c}\text { Sensitivity } \\
\text { Analysis Value }\end{array}$ & $\begin{array}{l}\text { Annual Cost } \\
\text { Saving (USD) }\end{array}$ & $\begin{array}{l}\text { Change from } \\
\text { Baseline (\%) }\end{array}$ & $\begin{array}{l}\text { Annual Cost } \\
\text { Saving (USD) }\end{array}$ & $\begin{array}{l}\text { Change from } \\
\text { Baseline (\%) }\end{array}$ \\
\hline $25 \%$ decrease in LAI cost reduction & $\$ 6,212$ & $\$ 4,596$ & 1,396 & -24.9 & 1,689 & -24.3 \\
\hline Lower patient response rate & $72.9 \%$ & $60.0 \%$ & 1,467 & -21.1 & 1,701 & -23.8 \\
\hline Increase baseline patient adherence (50\%) & $24.7 \%$ & $50.0 \%$ & 1,251 & -32.7 & 1,932 & -13.4 \\
\hline $10 \%$ increase in LAI prescribing rates among nonadherent patients & $78.0 \%$ & $68.0 \%$ & 1,549 & -16.7 & 2,100 & -5.9 \\
\hline $25 \%$ decrease in annual cost of switching or augmenting treatment & $\$ 4,079$ & $\$ 3,018$ & 1,764 & -5.1 & 2,134 & -4.4 \\
\hline Patient treatment tolerance falls & $7.0 \%$ & $20.0 \%$ & 1,846 & -0.7 & 2,155 & 3.4 \\
\hline No Change (Baseline) & & & 1,859 & 0.0 & 2,232 & 0.0 \\
\hline $25 \%$ increase in annual cost of switching or augmenting treatment & $\$ 4,079$ & $\$ 5,030$ & 1,904 & 2.4 & 2,303 & 3.2 \\
\hline $10 \%$ increase in LAI prescribing rates among nonadherent patients & $78.0 \%$ & $88.0 \%$ & 2,139 & 15.0 & 2,324 & 4.1 \\
\hline Improved dose titration results in cost savings & $\$ 0$ & $\$ 1,000$ & 2,023 & 8.8 & 2,447 & 9.7 \\
\hline $25 \%$ increase in LAI cost reduction & $\$ 6,212$ & $\$ 7,660$ & 2,272 & 22.2 & 2,748 & 23.1 \\
\hline Increased patient response rate & $72.9 \%$ & $90.0 \%$ & 2,379 & 27.9 & 2,997 & 34.3 \\
\hline
\end{tabular}

Note: Larger positive numbers indicate more cost saving; negative numbers indicate negative cost saving (i.e., costs increased).

aPoorly controlled patients include nonadherent patients and adherent patients who did not respond to the current treatment.

LAI=long-acting injectable; PDAI = patient drug adherence information; USD =U.S. dollars.

\section{Discussion}

This study demonstrated that providers with access to PDAI make more informed treatment decisions for nonadherent or adherent/poorly controlled patients, compared with providers without such access. Further, the treatment decisions made by providers with access to PDAI resulted in lower annual patient health care costs, particularly for poorly controlled patients. This change in cost was even greater for providers who frequently augmented therapy in poorly controlled patients.

Sources of PDAI include new technologies such as video monitoring and digital medicine systems, which measure not only a patient's medication possession, but also medication ingestion. These technologies likely provide more accurate estimates of adherence than other methods and have been shown to be feasible and practical for real-world use..$^{6,11-13,23-27}$ These new technologies have been tested in pilot studies across a variety of disease states such as tuberculosis, ${ }^{9-11,26,28}$ sickle cell disease, ${ }^{29}$ and heart failure and hypertension. ${ }^{9}$ Most recently, at least 1 method has been tested in patients with schizophrenia and bipolar disorder, ${ }^{6}$ with continued evaluation for its application in patients with serious mental illness. ${ }^{23,25}$ Broader use of VDOT or a digital medicine system may be able to improve providers' clinical decision making by providing more accurate PDAI.

The use of new technologies to more accurately measure PDAI helps providers distinguish between medication nonadherence and medication nonresponse and allows them to make more informed modifications to treatment regimens. In this study, access to PDAI altered the decisions providers made for poorly controlled patients. If poor disease control could be attributed to nonadherence based on PDAI, providers were more likely to switch the patient to an LAI antipsychotic than when PDAI was not available. Overall, the use of PDAI conferred lower annual health care costs per patient, especially for nonadherent patients and for patients of providers who frequently augmented antipsychotic therapy.

While PDAI cannot distinguish between those who would or would not respond to treatment if adherent, it can guide providers' treatment decisions for patients who are poorly controlled despite being adherent. For example, in this study, providers chose to increase the dose or switch to another oral antipsychotic more often when they had access to PDAI for adherent but poorly controlled patients than when they did not have access; however, they chose to switch to an LAI more often without PDAI. Indeed, access to PDAI led to the greatest reduction in costs for this group of patients.

The cost of generating PDAI was not included in this model. While one such technology has been approved by the U.S. Food and Drug Administration (FDA), ${ }^{30}$ its use in combination with an atypical antipsychotic has not yet been approved by the FDA for patients with schizophrenia in the United States. ${ }^{31}$ However, this study model estimated the extent to which the costs of acquiring PDAI could potentially be mitigated or increased by the effects of PDAI on physician behavior. There were no cost savings expected for patients whose schizophrenia is well controlled, but access to PDAI reduced costs for poorly controlled patients. Likewise, payers could generate more value per person if PDAI were available to those providers who typically rely on augmentation/polypharmacy therapy for nonresponsive patients. In this model, the largest reduction in annual health care costs per patient was observed 
for providers who frequently augment treatment of poorly controlled patients. Frequent augmentation and polypharmacy are widespread in the schizophrenia treatment landscape, with a reported incidence as high as $72 \%$ in 1 study. ${ }^{32-35}$ The findings from the provider survey indicate that providers without access to PDAI opted to augment the current therapy more often than those with access to PDAI.

\section{Limitations}

This study has a number of limitations. Principally, cost savings estimates depended on the case vignettes used to estimate realworld provider responses to PDAI. Although these vignettes were designed to capture a diverse mixture of patients with different ages, genders, and disease severity, they may not have been representative of the broader population of patients with schizophrenia. Future research should use real-world data to measure the effect of PDAI on cost once new technologiessuch as digital medicine-are approved by the FDA.

Further, this model assumed that PDAI was always accurate, but in the real world, the accuracy of any technology used to measure PDAI is imperfect. The validity of the model depends on the underlying parameters, and the baseline data may not be relevant for specific payers and/or patient subpopulations. Within the model, adherence was measured using PDC, which does not account for written prescriptions that are not filled or medication that is not ingested and may provide an estimate that differs substantially from another method of assessing adherence.

In addition, the estimated annual cost per patient incorporated only the value of improved provider decision making but did not include the cost savings as a result of increased patient engagement or patient actions to improve their own adherence. Within the current model structure, the sensitivity analysis revealed that cost savings estimates were particularly sensitive to estimates of the ability of LAIs to improve adherence and lead to a sustained patient response. Finally, if newer, more effective, treatments become available, ${ }^{36}$ then current response rates may be higher, which would likely increase expected cost savings. Alternatively, if some treatments used to augment therapy become generic, the cost of unnecessary augmentation may decrease over time as drug prices decrease because of the loss of exclusivity cost savings. ${ }^{37}$

\section{Conclusions}

Access to PDAI appears to improve provider decision making by ruling out nonadherence as a reason for medication nonresponse and clearly leads to lower annual health care costs. Future research is needed to evaluate how new technologies that monitor adherence affect health and economic outcomes among patients with serious mental illness.

\section{Authors}

JASON SHAFRIN, PhD, and TAYLOR T. SCHWARTZ, MPH, Precision Health Economics, Los Angeles, California. DARIUS N. LAKDAWALLA, PhD, Schaeffer Center for Health Policy and Economics, University of Southern California, Los Angeles. FELICIA M. FORMA, BSc, Otsuka Pharmaceutical Development $E$ Commercialization, Princeton, New Jersey.

AUTHOR CORRESPONDENCE: Jason Shafrin, PhD, Precision Health Economics, 11100 Santa Monica Blvd., Los Angeles, CA 90025.

Tel.: 310.984.7705; E-mail: jason.shafrin@precisionhealtheconomics.com.

\section{DISCLOSURES}

This study and medical writing assistance was funded by Otsuka Pharmaceutical Development \& Commercialization. Shafrin and Schwartz are employees of Precision Health Economics, which received funding from Otsuka Pharmaceutical Development \& Commercialization in support of this study. Lakdawalla is Chief Scientific Officer and a founding partner of Precision Health Economics. Schwartz is a consultant for Otsuka Pharmaceutical Development \& Commercialization, and Forma is an employee of Otsuka Pharmaceutical Development \& Commercialization.

The authors presented the abstract for this study as a poster presentation at the AMCP Managed Care \& Specialty Pharmacy Annual Meeting, April 19-22, 2016, San Francisco, California.

All authors contributed equally to the study design, data collection and analysis, and the writing and revision of the manuscript.

\section{ACKNOWLEDGMENTS}

Editorial assistance for manuscript development was provided by Jessica Holzhauer at C4 MedSolutions, Yardley, Pennsylvania.

\section{REFERENCES}

1. Kane JM, Kishimoto T, Correll CU. Non-adherence to medication in patients with psychotic disorders: epidemiology, contributing factors and management strategies. World Psychiatry. 2013;12(3):216-26.

2. Cloutier M, Aigbogun MS, Guerin A, et al. The economic burden of schizophrenia in the United States in 2013. J Clin Psychiatry. 2016;77(6):764-71.

3. Ascher-Svanum H, Faries DE, Zhu B, Ernst FR, Swartz MS, Swanson JW Medication adherence and long-term functional outcomes in the treatment of schizophrenia in usual care. J Clin Psychiatry. 2006;67(3):453-60.

4. Haddad PM, Brain C, Scott J. Nonadherence with antipsychotic medication in schizophrenia: challenges and management strategies. Patient Relat Outcome Meas. 2014;5:43-62

5. Sajatovic M, Velligan DI, Weiden PJ, Valenstein MA, Ogedegbe G Measurement of psychiatric treatment adherence. J Psychosom Res. 2010;69(6):591-99.

6. Kane JM, Perlis RH, DiCarlo LA, Au-Yeung K, Duong J, Petrides G. First experience with a wireless system incorporating physiologic assessments and direct confirmation of digital tablet ingestions in ambulatory patients with schizophrenia or bipolar disorder. J Clin Psychiatry. 2013;74(6):e533-40.

7. Velligan DI, Lam YW, Glahn DC, et al. Defining and assessing adherence to oral antipsychotics: a review of the literature. Schizophr Bull. 2006;32(4):724-42.

8. Stephenson JJ, Tunceli O, Gu T, et al. Adherence to oral second-generation antipsychotic medications in patients with schizophrenia and bipolar disorder: physicians' perceptions of adherence vs. pharmacy claims. Int J Clin Pract. 2012;66(6):565-73. 


\section{Estimating the Value of New Technologies That Provide More Accurate Drug Adherence Information to Providers for Their Patients with Schizophrenia}

9. Au-Yeung KY, Moon GD, Robertson TL, et al. Early clinical experience with networked system for promoting patient self-management. Am J Manag Care. 2011;17(7):e277-87.

10. Belknap R, Weis S, Brookens A, et al. Feasibility of an ingestible sensorbased system for monitoring adherence to tuberculosis therapy. PLoS One. 2013;8(1):e53373.

11. Garfein RS, Collins K, Munoz F, et al. Feasibility of tuberculosis treatment monitoring by video directly observed therapy: a binational pilot study. Int J Tuberc Lung Dis. 2015;19(9):1057-64.

12. Mirsaeidi M, Farshidpour M, Banks-Tripp D, Hashmi S, Kujoth C, Schraufnagel D. Video directly observed therapy for treatment of tuberculosis is patient-oriented and cost-effective. Eur Respir J. 2015;46(3):871-74.

13. Hafezi H, Robertson TL, Moon GD, Au-Yeung KY, Zdeblick MJ, Savage GM. An ingestible sensor for measuring medication adherence. IEEE Trans Biomed Eng. 2015;62(1):99-109.

14. Marder SR, McQuade RD, Stock E, et al. Aripiprazole in the treatment of schizophrenia: safety and tolerability in short-term, placebo-controlled trials. Schizophr Res. 2003;61(2-3):123-36.

15. Pigott TA, Carson WH, Saha AR, Torbeyns AR, Stock EG, Ingenito GG. Aripiprazole for the prevention of relapse in stabilized patients with chronic schizophrenia: a placebo-controlled 26-week study. J Clin Psychiatry. 2003;64(9):1048-56

16. Hess LM, Raebel MA, Conner DA, Malone DC. Measurement of adherence in pharmacy administrative databases: a proposal for standard definitions and preferred measures. Ann Pharmacother. 2006;40(7-8):1280-88.

17. Faries D, Ascher-Svanum H, Zhu B, Correll C, Kane J. Antipsychotic monotherapy and polypharmacy in the naturalistic treatment of schizophrenia with atypical antipsychotics. BMC Psychiatry. 2005;5:26.

18. Faries DE, Ascher-Svanum H, Nyhuis AW, Kinon BJ. Clinical and economic ramifications of switching antipsychotics in the treatment of schizophrenia. BMC Psychiatry. 2009;9:54.

19. Valuck RJ, Morrato EH, Dodd S, Oderda G, Haxby DG, Allen R. How expensive is antipsychotic polypharmacy? Experience from five U.S. state Medicaid programs. Curr Med Res Opin. 2007;23(10):2567-76.

20. Lin J, Wong B, Offord S, Mirski D. Healthcare cost reductions associated with the use of LAI formulations of antipsychotic medications versus oral among patients with schizophrenia. J Behav Health Serv Res. 2013;40(3):355-66.

21. Bureau of Labor Statistics. CPI inflation calculator. 2016. Available at: http:// www.bls.gov/data/inflation_calculator.htm. Accessed September 19, 2016.

22. Faries DE, Nyhuis AW, Ascher-Svanum H. Methodological issues in assessing changes in costs pre- and post-medication switch: a schizophrenia study example. Cost Eff Resour Alloc. 2009;7:11.

23. Rohatagi S, Profit D, Hatch A, Zhao C, Docherty J, Peters-Strickland T. Optimization of a digital medicine system in psychiatry. J Clin Psychiatry. August 2, 2016. Epub ahead of print. Available at: http://www.psychiatrist. com/JCP/article/Pages/2016/aheadofprint/16m10693.aspx. Accessed September 19, 2016

24. Proteus Digital Health. U.S. FDA accepts first digital medicine new drug application for Otsuka and Proteus Digital Health. September 10, 2015. Available at: http://www.proteus.com/press-releases/u-s-fda-accepts-firstdigital-medicine-new-drug-application-for-otsuka-and-proteus-digitalhealth/. Accessed September 19, 2016.
25. Profit D, Rohatagi S, Zhao C, Hatch A, Docherty JP, Peters-Strickland TS. Developing a digital medicine system in psychiatry: ingestion detection rate and latency period. J Clin Psychiatry. July 5, 2016. Epub ahead of print. Available at: http://www.psychiatrist.com/JCP/article/Pages/2016/ aheadofprint/16m10643.aspx. Accesed September 19, 2016.

26. Krueger K, Ruby D, Cooley P, et al. Videophone utilization as an alternative to directly observed therapy for tuberculosis. Int J Tuberc Lung Dis. 2010;14(6):779-81.

27. Minnesota Department of Health. Video directly observed therapy (VDOT) tool kit. 2016. Available at: http://www.health.state.mn.us/divs/ idepc/diseases/tb/lph/vdot/index.html. Accessed September 19, 2016.

28. Chuck C, Robinson E, Macaraig M, Alexander M, Burzynski J. Enhancing management of tuberculosis treatment with video directly observed therapy in New York City. Int J Tuberc Lung Dis. 2016;20(5):588-93.

29. Creary SE, Gladwin MT, Byrne M, Hildesheim M, Krishnamurti L. A pilot study of electronic directly observed therapy to improve hydroxyurea adherence in pediatric patients with sickle-cell disease. Pediatr Blood Cancer. 2014;61(6):1068-73

30. U.S. Food and Drug Administration. Evaluation of automatic class III designation (de novo) for proteus personal monitor including ingestion event marker. Available at: http://www.accessdata.fda.gov/cdrh_docs/reviews/ k113070.pdf. Accessed September 19, 2016.

31. Lawrence S. Updated: FDA rejects Otsuka, Proteus pill with medication adherence monitoring. FierceBiotech. April 27, 2016. Available at: http:// www.fiercebiotech.com/medical-devices/updated-fda-rejects-otsuka-proteuspill-medication-adherence-monitoring. Accessed September 19, 2016.

32. Jacob S, Ibrahim MM, Mohammed F. Polypharmacy in the management of patients with schizophrenia on risperidone in a tertiary-care hospital in Malaysia. Ment Health Fam Med. 2013;10(1):37-43.

33. Broekema WJ, de Groot IW, van Harten PN. Simultaneous prescribing of atypical antipsychotics, conventional antipsychotics and anticholinergics-a European study. Pharm World Sci. 2007;29(3):126-30.

34. De las Cuevas C, Sanz EJ. Polypharmacy in psychiatric practice in the Canary Islands. BMC Psychiatry. 2004:4:18.

35. Zhu B, Ascher-Svanum H, Faries DE, Correll CU, Kane JM. Cost of antipsychotic polypharmacy in the treatment of schizophrenia. BMC Psychiatry. 2008;8:19.

36. REXULTI (brexpiprazole) tablets, for oral use. Otsuka Pharmaceutical Co. Revised July 2015. Available at: https://www.accessdata.fda.gov/drugsatfda_docs/label/2015/205422s000lbl.pdf. Accessed September 19, 2016.

37. IMS Institute for Healthcare Informatics. Price declines after branded medicines lose exclusivity in the U.S. January 2016. Available at: https:// www.imshealth.com/files/web/IMSH\%20Institute/Healthcare\%20Briefs/ Price_Declines_after_Branded_Medicines_Lose_Exclusivity.pdf. Accessed September 19, 2016.

38. Kane JM, Carson WH, Saha AR, et al. Efficacy and safety of aripiprazole and haloperidol versus placebo in patients with schizophrenia and schizoaffective disorder. J Clin Psychiatry. 2002;63(9):763-71. 